\title{
Career Roles among the Teaching Staff in Palestine Technical University - Kadoorie and Al-Huson University College According to Their Points of View
}

\author{
Hussam Hosni Al-Qassim ${ }^{1}$ \\ ${ }^{1}$ Faculty of Arts and Educational Sciences, Department of Technological Education, Palestine Technical \\ University Kadoori, Palestine \\ Correspondence: Hussam Hosni Al-Qassim, Faculty of Arts and Educational Sciences, Department of \\ Technological Education, Palestine Technical University Kadoori, Palestine.
}

Received: February 2, 2021

Accepted: February 24, 2021

Online Published: March 3, 2021

doi:10.5539/mas.v15n2p9

URL: https://doi.org/10.5539/mas.v15n2p9

\begin{abstract}
This study aimed to find out the degree of practicing career roles among faculty members at Palestine Technical University - Khudouri and Al-Huson University College from their point of view, and knowing the effect of study variables (university, college, years of experience, academic rank) on the degree of practicing career roles. The study was conducted in the first semester of the academic year (2021/2020), when a stratified random sample was chosen from (149) faculty members, i.e., $30 \%$ of the study population, which is teaching staff at Palestine Technical University and Al-Huson University College who numbered (497) individuals, and to achieve this goal, a descriptive approach appropriate to the nature of this study was used. A questionnaire consisting of (30) items was designed and distributed in three areas: teaching, scientific research, and community service. The validity and reliability of the study tool were verified. The stability factor was $(0.91)$. The study reached the following results: The field of teaching got the first place in practice, then the field of scientific research, and finally the field of community service, as the study showed that there were no statistically significant differences between the averages of the sample members' estimates attributable to the variables (university, college, years of experience, and rank The academy, and the study recommended the necessity of holding training workshops, and meetings for faculty members at Palestine Technical University and Al-Huson University College, to transfer skills, exchange experiences and knowledge, in addition to developing creativity and solving problems in order to serve the local community, in addition to strengthening the relationship between the university and the local community. By providing the necessary scientific research and educational and cultural activities that help in developing the local community.
\end{abstract}

Keywords: career roles, faculty members, Palestine Technical University - Khadoori, Al-Huson University College

\section{Introduction}

The career roles of faculty members in Arab and foreign universities do not differ significantly, mainly as they are focused on one goal and achievement, which is to serve the university to which the faculty member belongs and the local community around him, and it is worth noting that there is a difference in the qualitative and quantitative values provided by members The teaching staff, whether for the benefit of the university, for scientific research, or for the service of the local community, and in light of the global and accelerating changes and the challenges of the current century, especially technological challenges, the job role of a faculty member has changed from a transmitter of knowledge and science to a learner and trainee and always keeps pace with global changes to grow and develop academically and professionally to achieve his job. In light of this acceleration of changes in different aspects of life (Krishnakumar, 2011), as his tasks go beyond the function of education to solve the problems of society through scientific research and investigation and the exercise of his educational and guidance tasks, and other roles to contribute to building the integrated personality of the learner (Matouk, 2016). Therefore, any defect in the preparation process will negatively affect the job role of the faculty member and the quality and quality of education. The Arab human development on university education and teaching methods in it led to the decline of the educational quality indicators in most Arab universities to less than $(60 \%)$ according to the standards in force, and the poor teaching performance of the faculty members was 
one of the main factors in the quality of higher education. (Regional Office for the Arab States, 2013)

The quality of universities and higher education institutions in the Arab world depends on their quality. The persevering and distinguished faculty member develops plans, programs, and advanced curricula that keep pace with modern technology and works to achieve required educational outcomes, in addition to these programs, plans, and curricula that strengthen relations between the local community Education is for the sake of developing national development programs and contributing to scientific research, which will contribute to raising the status of the academic reputation of the educational institution to which the faculty member belongs, and for the university to achieve its goals, chiefly building a promising generation, and serving the local community through scientific research, it requires members of the teaching in it is to fully exercise its functional roles.

\subsection{Problem Statement}

There are many deficiencies in the reality of university education in the Arab world in general. Al-Khatib (2001) mentioned that university education in Jordan suffers from several problems and challenges, the most important of which is the low quality of education and the weak contributions of universities in scientific research and community service compared to countries in the developed world. Moreover, this is also the case for Palestinian universities, and in light of what c The Palestinian and Jordanian universities face internal challenges imposed by local communities and external challenges represented in scientific and technological progress. This study determined the degree of practicing career roles among faculty members at Palestine Technical University Khadouri and Al-Huson University College, and through the above, the study problem was identified in the answer. The following questions:

First question: What is the degree of practicing functional roles among the faculty members at Palestine Technical University - Khadouri and Al-Huson University College?

Second question: Are there statistically significant differences at the significance level $(0.05 \geq \alpha)$ between the averages of the sample's estimates of the degree of their practicing the career roles according to the different variables (university, college, years of experience, and academic rank).

\subsection{Study Hypotheses}

The study questions emerged from the following null hypotheses:

First hypothesis: There are no statistically significant differences at the significance level between the averages of the study sample's estimates of the degree of their exercise of functional roles according to the university variable.

Second hypothesis: There are no statistically significant differences at the significance level $(\alpha \leq 0.05)$ among the study sample's average estimates of the degree of their practicing the career roles according to the college variable.

Third hypothesis: There are no statistically significant differences at the level of significance $((\alpha \leq 0.05$ among the average estimates of the study sample of the degree of their practicing the career roles according to the years of experience variable.

Fourth hypothesis: There are no statistically significant differences at the level of significance $(\alpha \leq 0.05)$ among the averages of the study sample's estimates of the degree of their practicing career roles according to the academic rank variable.

\subsection{Objectives of the Study}

The study aimed to achieve the following objectives:

- Identify the degree of practicing career roles among faculty members at Palestine Technical University - Khadouri and Al-Huson University College.

- Knowing the significance of the statistical differences in the degree of practicing career roles among faculty members at Palestine Technical University - Khadouri, and Al-Huson University College, according to the variables: (university, college, years of experience, and academic rank).

\subsection{The Significance of the Study}

The importance of the current study lies in the following:

Knowing the career roles of faculty members at Palestine Technical University - Khadouri and Al-Huson University College as a basis for the two universities' educational process's success. 
- Enlightening the faculty members at Palestine Technical University - Khadouri and Al-Huson University College of the degree of their practicing the career roles required of them.

- In light of the study results, that can help those in charge of managing the two universities to develop the job numbers for faculty members.

The study provides several recommendations to improve and develop faculty members' career roles at Palestine Technical University - Khadouri, and Al-Huson University College.

\subsection{Study Limitations}

The results of this study can be generalized within the limits of the following aspects:

Human Limitations: The study procedures were carried out on a sample of faculty members at Palestine Technical University Khadouri and Al-Huson University College - Al-Balqa Applied University.

Spatial Limitations: The study took place at Palestine Technical University - Khadouri and Al-Huson University College - Al-Balqa Applied University.

Temporal Limitations: This study was conducted during the first semester of the academic year (2020/2021).

\subsection{Terms of Study}

- Career roles: the jobs performed by faculty members in universities, including teaching, scientific research, and community service.

- Palestine Technical University - Khadouri: one of the public universities that are affiliated with the Ministry of Higher Education in Palestine and is located in the city of Tulkarm, and it grants diplomas, bachelors, and master degrees for many scientific and human disciplines.

- Al-Huson University College: a college affiliated with the Al-Balqa Applied University, located in the city of Al-Huson In Jordan, diploma and bachelor's degrees are awarded to many scientific and humanitarian disciplines.

Faculty member: anyone who teaches at Palestine Technical University - Khadouri and holds a master's degree as a minimum.

- Degree of practice: the level of behavior performed by a faculty member related to career roles, and this behavior is actual action, and this practice is measured by the degrees that are defined in the progressive scale used in the study tool.

\subsection{Theoretical Framework and Literature Review}

The quality of higher education institutions depends on the quality of the members of the teaching staff therein. A distinguished person sets advanced programs and curricula that aim to achieve the required educational outcomes and document the relationship between him and the local community in the development of national development programs, and contribute to scientific research for practical insights to solve human development problems, which contributes to achieving the academic standing and reputation of the academic institution to which he belongs to her. In order for the university to achieve its goals, the faculty member must exercise his academic roles, namely:

\section{First Chapter: Teaching}

Teaching at the university is one of the faculty members' primary services, as they leave clear impacts on the local community in general and on students in particular. Teaching is an activity practiced by a faculty member to develop the entire education process, contributing to the development of human resources, raising its efficiency, and developing its multiple capabilities for work fields. Al-Amayreh (2006) defined teaching performance as "the degree to which a faculty member carries out the teaching-learning-tasks entrusted to him and the practices, activities, and behaviors he exerts concerning his various tasks in expression and behavior."

Al-Farra (2004) defined it as a behavioral expression of the teacher's possession of teaching skills. University teaching is responsible for preparing intellectual, scientific, literary, and professional leaders at various levels that serve the local community's various institutions and sectors. The impact of these leaders is not limited to specific aspects of the university. However, it extends to the university's development to face everything new. It is impossible to bring about an in-depth and comprehensive change in society unless there are qualified academically and technically leaders who are convinced of development and change and can achieve effective teaching.

Although contemporary teaching is applied, selective, sophisticated science, it is also a comprehensive educational process that considers all the factors constituting teaching and learning to achieve educational goals, 
and teaching and that is a process of social interaction whose means are: thought, senses, emotion, and language (Hariri, 2010).

Furthermore, the process through which the university can contribute to the development of human resources, which has been given great importance, given that the discovery and investment of natural resources, the mobilization of capital, the development of goods and their production, and the conduct of business needs skilled human resources. A country that cannot develop its human resources does not, as a result, be able to build anything. Through its educational function, the university balances human resources, prepares professional competencies for the various developmental sectors, and preserves the culture and strengthens national identity, whereas both aspects of university education are essential factors in community development and building (Millcy, 2003).

Therefore, university teaching is one of the most critical jobs that universities perform in preparing students for future life. It provides them with specialized knowledge, positive and valuable behavioral trends, and all the scientific and practical skills necessary to qualify them to become influential community service members. The university's excellence measure depends on its possession of highly qualified faculty members, and it provides with all the conditions and capabilities of a suitable academic atmosphere and various services that contribute to the quality of the educational process in order to be able to meet the needs of comprehensive development and the requirements of the accelerated age (Froehwald, 2003).

In order for a university professor to fully exercise the teaching function, he must be proficient in the field of His specialization is widely read, familiar with the latest educational theories and applications, presenting the topics of the lesson clearly and logically, and taking into account the individual differences between students (Hariri, 2010). He also works to provide the appropriate atmosphere for the educational process's success, including guidance, counseling, human relations, and using educational aids. He also connects between the practical and theoretical aspects, is committed to discussion and dialogue, accepts other scientific opinions, pays attention to the students' social and economic conditions, raises students' enthusiasm for the lesson and discussion using various methods of teaching that focus on self-learning and analytical, creative thinking (Ma'ani, 2002).

\section{Second Chapter: Scientific Research}

The need for scientific research in our present time is more critical than ever before, as the world is in a race to reach the possible amount of accurate and fruitful knowledge that guarantees the comfort and well-being of human beings and guarantees them superiority over others. Since the university is a productive institution that works to enrich knowledge, develop productive arts, prepare human competencies, build generations and raise them scientifically, intellectually, culturally, politically, socially, and spiritually. It works to increase the balance of knowledge, benefit from the fruits of the scientific heritage, intellectual production, human wealth development, and raise its productive efficiency and cultural and social level. Thus, the university represents a scientific community concerned with searching for scientific truth (Harahsha, 2013). Scientific research occupies a vital position within a faculty member's responsibilities in universities, requiring him to undertake an organized scientific effort to develop human knowledge in his field of specialization and teaching, and the university at present undertakes research. Scientific research is a concern the universities are committed to providing the appropriate atmosphere and the necessary capabilities for its faculty members to conduct original and innovative scientific research (Al-Shaksy, 2006).

Scientific research is an "organized intellectual process carried out by a person called (the researcher) in order to find facts on a particular issue or problem called (The research problem (by following an organized scientific method called (research method) in order to reach appropriate solutions for treatment or to generalized results for similar problems called research results" (Zewailf \& Al-Tarawanah, 1998).

Scientific research is one of the crucial roles of the faculty member in university work; in the universities of developed countries, the scientific research activities carried out by faculty members represent about (33\%) of their job burden, while these activities do not represent more than $(5 \%)$ of the burdens of university faculty members in Arab countries, and scientific research is an essential and vital component of The university's life as a scientific and intellectual institution, and the reputation of the university is linked to the research it publishes, and the importance of the scientific research function for university professors appears; Because they possess high capabilities of organized thinking and innovation, and the ability to employ and use knowledge with a new understanding of the past for the sake of a new start for the present and a forward-looking vision for the future (Jess, 2013).

According to its utility, scientific research is classified into pioneering research in which new knowledge is discovered, an old problem is solved, and research in which general materials and knowledge are collected, 
disclosed, or presented for comparison, analysis and criticism. The first type has a more significant role in expanding human knowledge horizons and advancing scientific research at the university. Therefore, the following should be taken into account (Ma'ani, 2002):

1. Developing integrated and studied plans for scientific studies conducted by the university in response to the community's needs.

2. Providing laboratories and modern scientific instruments necessary to conduct research.

3. Providing research references and libraries and circulating publications and scientific journals.

4. Providing the right science atmosphere to help researchers with production and creativity.

5. Holding scientific conferences, seminars, and symposia dealing with the community problems and research issues.

6. Encouraging participation in scientific conferences at regional and global levels.

7. Granting incentives to universities that produce scientific research compatible with the needs of the community.

\section{Third Chapter: Community Service}

The role of universities in community service is based on the fact that it is the most advanced and influential institution in societies' lives. It is considered the most important tributary of development that deals with the requirements of these societies and their various needs and their progress in all fields, by revealing their problems and finding appropriate solutions for them, and by revealing the talents and capabilities of their members and work to refine and accentuate it (Wasus, Al-Jawarneh, \& Al-Attiyat, 2015).

The connection of universities with their societies and the provision of a set of roles, activities, and services has become a necessity imposed by recent changes so that the university serving its community is no longer optional. A faculty member has a vital role in providing community services. That must be taken into account when selecting, preparing and evaluating them, identifying the most significant obstacles that prevent them from performing these roles in the best way, and proposing solutions (Wani \& Ahmed, 2005). The faculty members' responsibility is to link the university with the community, which helps to open up to society, interact with it, work on its development, solve problems, and reasonably use its resources. They work to educate members surrounding the community, both at the local and national levels, through their books and papers they distribute to scientific bodies and by radio conversations or television.

Ammar (1996) defines the university's local community service as the university's dissemination of the scientific knowledge related to sciences taught in college and enlightening in theory or practice. It also evaluates the community's institutions, recommends solutions for their problems, presents perceptions and alternatives to society, and spreads the correct educational thought. And that is achieved by developing faculty members' applied skills that can be fulfilled by increasing their expertise and capabilities in developing study plans, motivating them towards scientific research, and contributing to developing students' skills and experiences. (Kors, 1998).

Hassan (1995) pointed out that the role of the university towards the local community is as in the following:

1. Providing the community with its needs for trained cadres that cope with recent changes.

2. Training students on spreading health awareness, literacy, etc.

3. Raising awareness of the problems of the community in general and the local community.

4. Linking universities with productive institutions.

5. Linking between the quality of scientific research and the problems of the local community.

6. Interpreting and publishing research results to benefit from them in the community.

7. Conducting comprehensive environmental research that addresses overlapping problems.

\section{Literature Review}

Wasus, Al-Jawarneh, and Al-Attiyat (2015) aimed to define the degree of faculty members' practice at Al-Hussein Bin Talal University for academic roles and demonstrate the impact of study variables (college, experience, academic degree) on the degree of practicing academic roles. To achieve this goal, the descriptive approach appropriate to the nature of this study was used, and a questionnaire was designed consisting of (46) items distributed into three areas: teaching, scientific research, and community service, as the study community included all the faculty members at Al-Hussein Bin Talal University, whose number reached (268), and a simple random 
sample was selected from the study population consisting of (135) members. The study results concluded that scientific research was ranked first in practice, then the teaching field, and finally community service. There were no significant differences between the averages of the sample members 'estimates attributable to the faculty variable except for the community service aspect and in favor of the scientific colleges 'estimates. Significant differences were found between the averages of the estimates. The sample members of the variable of academic rank and in favor of the rank of assistant professor and found statistically significant differences between the averages of the sample members 'estimates of the experience variable and in favor of estimates from their experience from (1-5) in the two fields of comparison. In light of these results, training workshops were recommended for faculty members and presenting new skills in training workshops to the classroom.

Al-Tal and Al-Sarayra (2013) aimed to identify the degree of interest of Mutah University in the quality of its role in serving the local community in light of the university's estimates faculty and to reveal the effect of the applied study variables on these estimates, The researchers used a questionnaire of (36) items, and it was applied to (221) faculty members. The study found that the faculty members at Mu'tah University should pay attention to their role in serving the local community with a medium degree.

Al-Sarayra (2011) indicated that the level of performance is recognized. The researcher developed the study questionnaire, and then it was applied to a sample consisting of (77) academic department heads chosen in a simple random way. To answer the study questions, the arithmetic averages and standard deviations were calculated. The study results showed that the level of the job performance of faculty members was high, reaching (3.78) out of (5) scores, and the results indicated no significant differences due to the variables. The researcher is for universities to enhance the job performance of faculty members in them, to know their needs and desires to achieve what is possible and to satisfy them, and to provide a system of incentives, material and moral, because of their positive impact on the province, to the level of high job performance.

Al-Amayreh (2006) aimed to identify the degree of performance of faculty members at Al-Isra Private University for their educational tasks from their students' viewpoint. A questionnaire was distributed to a sample consisting of (29) faculty members and (271) students. The study concluded that the evaluation of the faculty members themselves scored high, and students rated their teaching tasks close to the degree of neutrality.

Millcy (2003) aimed at providing colleges with information on the performance of faculty members. There were 874 students from three different universities in the United States of America were asked to determine the disturbing habits that students noticed in their professors' performance. The study results showed that failure to organize the teaching process, sputtering during the explanation, relying on giving lectures, presenting them in a low voice, and the low grades of students are habits practiced by the faculty members.

Boyd and Rush (2002) aimed to find out the reality of the contributions of faculty members at the University of Santa Cruz, California, in community service, and the results of the study found that $80 \%$ of the respondents practice community service tasks, and $21 \%$ of them practice environmental services. Moreover, $15 \%$ practice humanitarian services and 3\% practice religious services, and it has shown that the university has helped faculty members provide available resources and continuous encouragement for them and create courses related to community service.

Jeanette (2001) aimed to measure the effect of applying performance indicators on the teaching and research activities of (152) faculty members in four Australian universities. Most of the sample individuals indicated an increase in pressure to focus on activities that It is measured through performance indicators in the field of teaching and research, and the majority of participants also reported a change in the way they teach and research, and this was to direct more attention towards obtaining external research grants and publishing research in international periodicals. Some professors using methods to increase the number of what they publish, such as presenting short job papers and scientific research, has occupied a high priority over teaching.

\section{Commenting on previous studies}

The points of agreement and difference between the previous studies and the current study of four aspects as follows:

1. The method: Most of the previous studies agreed with the current study in using the descriptive method such as (Wasus, Al-Jawarneh, and Al-Attiyat, 2015).

2. The used tools: Most of the previous studies agreed with the current study using the questionnaire as a primary tool, such as (Al-Amayreh, 2006) and (Al-Tal and Al-Sarayra, 2013).

3. Society and the sample: Some previous studies agreed with the current study in that they dealt with faculty members as a community, and a sample was taken from them, such as Boyd and Rush, 2002, and 
Jeanette (2001).

4. Study variables: The previous studies differed in the variables of the study as a whole or as part according to the subject of the study, such as (Sarayreh, 2013) and (Al-Amayreh, 2006), while the current study depended on the following variables: (university, college, years of experience, academic rank).

\section{What distinguishes the current study?}

The current study - as far as the researcher knows - is the first of its kind that deals with the career roles of faculty members in Palestinian universities in general and Palestine Technical University - in particular, which helps in opening the way for the other researchers to conduct more studies based on the results of this research.

1. The current study tried to bridge the gap in local Palestinian studies dealing with academic roles, as there is a dearth of local studies - to the best of researchers' knowledge- that dealt with the functional variable.

2. This study aimed to identify the degree of practicing career roles among faculty members at Palestine Technical University - Khadouri.

\section{Study Methodology and Procedures}

\subsection{Study Methodology}

The descriptive-analytical approach was used in the current research due to its relevance to the subject.

\subsection{Sample and Sampling}

All faculty members at Palestine Technical University - Khadouri and Al-Huson University College, for the semester first of the academic year (2019/2020), as their number reached (497) members, according to the statistics of the Human Resources Department at the university And Al-Huson University College. A random sample was selected which consisted of (149) members, and thus the percentage of the sample to the study population reached (30\%). Table 1 shows the characteristics of the study sample.

Table 1. Characteristics of the study sample

\begin{tabular}{llll}
\hline Variable & Variable Level & Repetition & Percentage \\
\hline University & Palestine Technical University & 104 & $69 \%$ \\
\multirow{2}{*}{ Total } & Al-Huson College University & 45 & $31 \%$ \\
\multirow{3}{*}{ Years of experience } & Humanitarian & 79 & $53 \%$ \\
& Scientific & 70 & $47 \%$ \\
& Less than 5 years & 48 & $32 \%$ \\
Academic Rank & About 5-10 Years & 67 & $44 \%$ \\
& More than 10 years & 34 & $24 \%$ \\
& Lecturer & 77 & $52 \%$ \\
& Assistant Professor & 48 & $32 \%$ \\
& Associate Professor & 19 & $13 \%$ \\
& Professor & 5 & $3 \%$ \\
\hline
\end{tabular}

\subsection{Study Instrument}

To achieve the objectives of the study, the researcher developed after referring to theoretical literature and previous studies as a study (Al-Sarayra, 2011) and the study (Matouk, 2016) to develop a questionnaire that was initially formed of two parts, and it is as follows:

The first section: General information about the respondents from the faculty and their demographic variables.

The second section: includes the domains of career roles, which are three areas as follows:

The first field: teaching, and the number of its items is (10) items.

The second field: scientific research and its number is (10) items.

The third field: community service and its number is (10) items. 


\subsection{Instrument Validity}

First: reviewers' validity: To assess this type of validity, a questionnaire for career roles was presented to a group of qualified and experienced reviewers who hold a Ph.D. in education, teaching methods, curricula, sciences, and educational administration, and with experienced workers in the educational field, their number is (12), as the items of the questionnaire were judged in terms of measuring what was set for it, the accuracy of the wording and the safety of the language, and suggesting appropriate amendments, addition, deletion or Transferring from one field to another, and after reviewing the reviewers' proposals, the questionnaire came out in its final form.

Second: The stability of the study tool: The researcher verified the stability of the study tool by calculating the stability coefficients according to the Cronbach's Alpha stability equation, and the reliability coefficient for the total degree of the functional roles tool was $(0.91)$, which is a high value that meets the purposes of scientific research.

\section{The key to correcting the scale:}

The researchers determined the average degree of response of the study sample by adopting the following weight scale:

-from (1-2.49) a degree of weak practice

-from (2.50-3.49) a degree of intermediate practice

-from (3.50-5) a degree of high practice.

\section{Presenting and Discussing the Results}

After collecting data from the study sample, the researchers calculated the arithmetic means and standard deviations.

Results related to the first question: What is the degree of occupational role exercise among faculty members at Palestine Technical University - Khadouri and Al-Huson University College from their point of view.

To answer this question, the researchers calculated the arithmetic mean and standard deviations of the sample member's estimates of the degree of their practicing the career roles. Table No. 2 illustrates this.

Table 2. The arithmetic averages and standard deviations of the sample individuals' estimates of the degree of their exercise of functional roles on the study fields arranged in descending order

\begin{tabular}{llllll}
\hline Number & Fields & $\begin{array}{l}\text { Arithmetic } \\
\text { Mean }\end{array}$ & $\begin{array}{l}\text { Standard } \\
\text { Deviation }\end{array}$ & Rank & Degree of Practice \\
\hline $\mathbf{1}$ & teaching & 4.22 & 0.40 & first & High \\
$\mathbf{2}$ & scientific research & 3.68 & 0.52 & second & High \\
$\mathbf{3}$ & community service & 3.57 & 0.42 & third & High \\
Total & & 3.82 & 0.35 & - & High \\
\hline
\end{tabular}

Table 2 shows that the field of teaching ranked first with arithmetic mean (4.22) and a standard deviation (0.40), and the field of scientific research came in second place with arithmetic mean (3.68) and a standard deviation (0.52) While the community service field came in the last place with arithmetic mean (3.57) and a standard deviation of (0.42). The mean of the sample estimates of the degree of academic roles' practice was $(0.35)$ and with a standard deviation (0.35). This result can be explained by the fact that there is a high level of awareness among the teaching staff at Palestine Technical University and Al-Huson University College for their career roles, so the degree of their practice is at a high level and explains the teaching staff being ranked first, mainly as it constitutes the teaching staff. All institutions of higher learning from universities and colleges in Palestine and Jordan participate in it. Trying faculty member focus on scientific basis and treatment theory and Applied, it came field scientific research second place because of high awareness importance scientific research, based evaluating process faculty infield scientific research member the two criteria continuing research activity research and production, and the scientific research inherent helps faculty member the uplifted land created professional interest field, either community service the last rank reflects effectiveness role faculty members at University Palestine technical College fort university in the local community and care service, by providing necessary expertise and guidance to community and activate community service Center at University More generally, as well as ongoing training activities by proposing appropriate scientific programs, working on developing their professional skills and competencies, providing advice and organizing conferences, seminars, and workshops serving the issues of the community. The arithmetic averages and standard deviations of the sample estimates were calculated on the items 
of the study axes, as they were as follows:

\section{A- The first field: Teaching}

The arithmetic means, and standard deviations of the sample estimates were calculated on this field's items, and Table 3 illustrates this:

Table 3. Arithmetic averages and standard deviations of the sample members' estimates on the field of teaching, in descending order

\begin{tabular}{|c|c|c|c|c|}
\hline No. & Item & $\begin{array}{l}\text { Arithmetic } \\
\text { Mean }\end{array}$ & $\begin{array}{l}\text { Standard } \\
\text { Deviation }\end{array}$ & $\begin{array}{l}\text { Degree of } \\
\text { Practice }\end{array}$ \\
\hline 3 & I adhere to the ethics of the academic job & 4.64 & 0.87 & High \\
\hline 7 & I choose references and scientific sources & 4.57 & 0.75 & High \\
\hline 1 & $\begin{array}{l}\text { I design the course plans with the nature } \\
\text { of the scientific subject }\end{array}$ & 4.48 & 0.75 & High \\
\hline 4 & $\begin{array}{l}\text { I practice both theoretical and scientific } \\
\text { education }\end{array}$ & 4.36 & 1.00 & High \\
\hline 5 & $\begin{array}{l}\text { I use the appropriate teaching method for } \\
\text { the subject of study }\end{array}$ & 4.23 & 0.82 & High \\
\hline 2 & $\begin{array}{l}\text { I use different teaching methods } \\
\text { according to the subject of study }\end{array}$ & 4.23 & 0.80 & High \\
\hline 8 & I seek to develop my academic abilities & 4.09 & 0.93 & High \\
\hline 6 & I use a variety of evaluation methods & 3.91 & 1.04 & High \\
\hline 10 & $\begin{array}{l}\text { I collaborate with my colleagues in the } \\
\text { development of academic courses }\end{array}$ & 3.87 & 1.24 & High \\
\hline 9 & $\begin{array}{l}\text { I encourage students to self-learning } \\
\text { skills }\end{array}$ & 3.86 & 1.10 & High \\
\hline \multicolumn{2}{|c|}{ Items as a whole } & 4.22 & 0.40 & High \\
\hline
\end{tabular}

Table 3 shows that Item (3), which states: "I adhere to the ethics of the academic job," occupied the first place with arithmetic mean (4.64) and a standard deviation (0.87). Item No. (7) came, and the text was: "I choose references and scientific sources. This result is since all faculty members are from the elite of society. Therefore, they are characterized by high morals, which drive them to fully adhere to the practical ethics stipulated in the two universities, in addition to the choice of appropriate scientific references by the faculty member for any course facilitate the process of understanding and comprehension by students and thus obtain high results.

Item No. (9), which states, "I encourage students to self-learning skills", ranked last with arithmetic mean (3.86) and a standard deviation (1.10). That is because of the faculty member's conviction that students are dependent and do not learn from their own will.

\section{B - The second field: scientific research}

The arithmetic means and standard deviations of the sample members 'estimates were calculated in this field's items. Table 4 illustrates this: 
Table 4. The arithmetic means and standard deviations of the sample members' estimates in the scientific research field, in descending order

\begin{tabular}{|c|c|c|c|c|}
\hline No. & Item & Arithmetic Mean & Standard Deviation & Degree of Practice \\
\hline 13 & $\begin{array}{l}\text { I conduct scientific research in } \\
\text { the field of specialization }\end{array}$ & 3.90 & 0.95 & High \\
\hline 16 & $\begin{array}{l}\text { I do joint research with } \\
\text { colleagues }\end{array}$ & 3.84 & 0.99 & High \\
\hline 15 & $\begin{array}{l}\text { I participate in local and } \\
\text { international scientific } \\
\text { conferences and seminars }\end{array}$ & 3.81 & 1.01 & High \\
\hline 14 & I use different search engines & 3.80 & 0.96 & High \\
\hline 11 & $\begin{array}{l}\text { I commit to ethics Scientific } \\
\text { research }\end{array}$ & 3.70 & 0.96 & High \\
\hline 18 & $\begin{array}{l}\text { I contact researchers in other } \\
\text { universities }\end{array}$ & 3.67 & 1.03 & High \\
\hline 12 & $\begin{array}{l}\text { I encourage the local community } \\
\text { to participate in scientific } \\
\text { research activities }\end{array}$ & 3.67 & 1.19 & High \\
\hline 17 & $\begin{array}{l}\text { I employ the results of scientific } \\
\text { research in developing } \\
\text { educational science }\end{array}$ & 3.65 & 1.06 & High \\
\hline 20 & $\begin{array}{l}\text { I employ the scientific } \\
\text { methodology in } \\
\text { educational problems }\end{array}$ & 3.41 & 1.12 & Medium \\
\hline 19 & $\begin{array}{l}\text { I work on the development of } \\
\text { scientific research skills among } \\
\text { students }\end{array}$ & 3.36 & 1.18 & Medium \\
\hline \multicolumn{2}{|c|}{ Items as a whole } & 3.68 & 0.42 & High \\
\hline
\end{tabular}

Table 4 shows that Item No. (13), which stated" I conduct scientific research in the field of specialization, "ranked first with arithmetic mean (3.90) and a standard deviation (0.95) Item No. (16), which reads" I do joint research with colleagues "came second, with arithmetic mean (3.84) and a standard deviation (0.99). This result is attributed to the promotion of the faculty member who does not complete published scientific research.

While Item No. (19), which is" I work on the development of scientific research skills among students ",was ranked last with an arithmetic mean (3.36) and a standard deviation (1.18). That is because university course plans do not require scientific research work by students, but rather, this research is limited to the scientific research course only.

\section{C- The third field: community service.}

The arithmetic means and standard deviations of the sample members' estimates were calculated on this field's items. Table 5 illustrates this: 
Table 5. Arithmetic averages and standard deviations of the sample members' estimates on the community service field in descending order

\begin{tabular}{|c|c|c|c|c|}
\hline No. & Item & $\begin{array}{l}\text { Average } \\
\text { Arithmetic }\end{array}$ & $\begin{array}{l}\text { Standard } \\
\text { Deviation }\end{array}$ & $\begin{array}{l}\text { Degree of } \\
\text { Practice }\end{array}$ \\
\hline 22 & I promote national culture among students & 3.87 & 0.85 & High \\
\hline 24 & $\begin{array}{l}\text { I do whatever work I am assigned to do to serve the } \\
\text { local community }\end{array}$ & 3.79 & 1.08 & High \\
\hline 27 & I connect Study topics with local community issues & 3.76 & 1.05 & High \\
\hline 28 & $\begin{array}{l}\text { I introduce community problems during the teaching } \\
\text { process in order to find a solution to them }\end{array}$ & 3.74 & 1.25 & High \\
\hline 23 & $\begin{array}{l}\text { I participate in curricular activities outside the } \\
\text { university }\end{array}$ & 3.73 & 1.16 & High \\
\hline 29 & $\begin{array}{l}\text { I encourage students to assume their responsibilities } \\
\text { towards the local community }\end{array}$ & 3.66 & 0.90 & High \\
\hline 26 & $\begin{array}{l}\text { I serve the community Local through participation in } \\
\text { cultural and social institutions }\end{array}$ & 3.51 & 1.21 & High \\
\hline 30 & $\begin{array}{l}\text { I seek to mobilize the local community to serve and } \\
\text { develop the university }\end{array}$ & 3.37 & 1.26 & Medium \\
\hline 21 & $\begin{array}{l}\text { I give advice and scientific information to the local } \\
\text { community }\end{array}$ & 3.36 & 1.08 & Medium \\
\hline 25 & I suggest ideas for advancing the local community & 2.91 & 1.25 & Medium \\
\hline \multicolumn{2}{|c|}{ Items as a whole } & 3.57 & & High \\
\hline
\end{tabular}

Table 5 shows Item No. (22), which stated, "I promote national culture among students," has been steadily ranked first. Arithmetic mean (3.87) and a standard deviation (0.85). Item No. (24), which is "I do whatever work I am assigned to do to serve the local community," came in second place, with an arithmetic mean (3.79) and a standard deviation (1.08). This result is attributed to all members of the committee.

Teaching in the two universities perpetuate patriotism, which is represented in defending the homeland and its natural resources and serving its community members in most lectures, seminars, and workshops.

While Item No. (25), which states, "I suggest ideas for advancing the local community," was ranked last with an average (2.91) and a standard deviation (1.25). The reason for that is that the ideas and activities which help the development and advancement of the local community come from outside the university and not from a faculty member's responsibility.

\subsection{Results Related to the Second Question}

Are there statistically significant differences at the significance level $(0.05 \geq \alpha)$ between the averages of the sample's estimates of the degree of their practicing functional roles according to the difference of variables (university, college, years of experience, academic rank).

The researcher answered the second study's question by examining the null hypotheses emanating from it, which are as follows:

Result of the first hypothesis: There are no statistically significant differences at the level of significance between the averages of the study sample's estimates of the degree to which they practice functional roles according to the university variable:

To examine this hypothesis, a T-test was used for independent samples (independent sample t-test) as shown in Table 6. 
Table 6. (t-test) results for the differences between the study sample's estimates of the degree of their exercise of functional roles depending on the university variable

\begin{tabular}{llllllll}
\hline Fields & University & No. & Arithmetic Mean & SD & Degrees of Freedom & T-Test & Level of Significance \\
\hline \multirow{2}{*}{ Total } & $\begin{array}{l}\text { Technical } \\
\text { Palestine } \\
\text { Khadoori }\end{array}$ & 104 & 3.84 & 0.23 & 147 & 1.79 & 0.08 \\
& $\begin{array}{l}\text { Al-Huson } \\
\text { University } \\
\text { College }\end{array}$ & 45 & 3.53 & & & & \\
\end{tabular}

As noticed from table 6 that there are no differences between the study sample's estimates of the degree of their practice of roles. Employment is attributed to the university variable according to the total degree. That may be attributed to the fact that both universities have the same career roles, especially that the Palestinian higher education law applied by Palestinian universities is very similar to the Jordanian higher education law applied by Jordanian universities.

Result of the second hypothesis: There are no statistically significant differences at the level of significance between the averages of the study sample's estimates of the degree to which they practice functional roles according to the college variable:

To test this hypothesis, a t-test was used for independent samples (Independent Sample t-test), as shown in table 7.

Table 7. The results of the t-test for the differences between the estimates of the study sample of the degree of their practicing the career roles according to the college variable

\begin{tabular}{llllllll}
\hline Fields & Overall & N. & $\begin{array}{l}\text { Arithmetic } \\
\text { Mean }\end{array}$ & SD & $\begin{array}{l}\text { Degrees of } \\
\text { Freedom }\end{array}$ & T-Test & $\begin{array}{l}\text { Level of } \\
\text { Significance }\end{array}$ \\
\hline Teaching & Humanity & 79 & 3.62 & 0.42 & 147 & 1.25 & 0.21 \\
& Scientific & 70 & 3.76 & 0.57 & & & \\
Scientific & Humanity & 79 & 3.91 & 0.94 & 147 & 1.09 & 0.24 \\
Research & Scientific & 70 & 4.16 & 0.40 & & 0.07 & 0.97 \\
Community & Humanity & 79 & 3.73 & 0.41 & 147 & & \\
Service & Scientific & 70 & 3.81 & 0.37 & & & 0.07 \\
Total score & Humanitarian & 79 & 3.72 & 0.30 & 147 & & \\
& Scientific & 70 & 3.86 & 0.39 & & & \\
\hline
\end{tabular}

As noticed in table 7, there are no differences between the study sample members' estimates of the degree of practicing career roles due to the faculty variable according to the total degree. That may be explained by the fact that all the two universities' colleges are equal scientific or humanism have the same role in teaching, scientific research, and community service.

The result of the third hypothesis: There are no statistically significant differences at the level of significance ( $\alpha$ $\leq 0.05$ ) among the average estimates of the study sample of the degree of their practicing the career roles according to the years of experience variable.

To test this hypothesis, the One-Way ANOVA test was used to extract the values of the arithmetic averages, standard deviations, degrees of freedom, the calculated (F) values, and the values of the level of statistical significance of the responses of the study sample to the total tool of the study, as shown in table 8 . 
Table 8. The results of the one-way analysis of variance test for the differences between the study sample's estimates of the degree of their practicing the career roles due to the years of experience variable

\begin{tabular}{lllllll}
\hline Domains & Source of Variance & $\begin{array}{l}\text { Total } \\
\text { Squares }\end{array}$ & $\begin{array}{l}\text { Degrees of } \\
\text { Freedom }\end{array}$ & $\begin{array}{l}\text { Mean } \\
\text { Squares }\end{array}$ & $\begin{array}{l}\text { Value of } \\
\text { Computerized p- }\end{array}$ & $\begin{array}{l}\text { Level of } \\
\text { Significance }\end{array}$ \\
\hline Teaching & Between Groups & 1.42 & 2 & 0.71 & 0.84 & 0.51 \\
& Within Groups & 123.32 & 146 & 0.84 & & \\
& Total & 124.74 & 148 & & & 0.31 \\
\hline $\begin{array}{l}\text { Scientific } \\
\text { research }\end{array}$ & Between Groups & 1.84 & 2 & 0.92 & 1.16 & \\
& Within Groups & 116.21 & 146 & 0.79 & & \\
& Total & 118.05 & 148 & & & \\
\hline Community & Between Groups & 2.75 & 2 & 1.37 & 1.90 & \\
& Within Groups & 106.34 & 146 & 0.72 & & \\
& Total & 109.09 & 148 & & & \\
\hline Total score & Between Groups & 2.03 & 2 & 1.01 & 1.18 \\
& Within Groups & 125.12 & 146 & 0.85 & & \\
& Total & & 148 & & & \\
\hline
\end{tabular}

As noticed from table 8 that there are no differences between the estimates of the study sample individuals to the degree of their practicing the functional roles attributable Years of experience vary according to the total degree, and this is since the faculty members in both universities, whether newly appointed or who have long years of work have the responsibility of the university teaching profession, scientific research and community service, especially that one of the conditions for promotion for any university professor requires achievements in scientific research And community service.

As a result of the fourth hypothesis: There are no statistically significant differences at the level of $(\alpha \leq 0.05)$ among the averages of the study sample's estimates of the degree of their practicing career roles according to the academic rank variable.

To test this hypothesis, a test was used single analysis variance (One-Way ANOVA) to extract values arithmetic averages and standard deviations and degrees freedom and values (F) calculated values level statistical significance of responses college tool to study, also including Table 9.

Table 9. The results of the one-way analysis of variance test for the differences between the study sample's estimates of the degree of their practicing the career roles due to the variable of academic rank

\begin{tabular}{lllllll}
\hline Domains & $\begin{array}{l}\text { Source of } \\
\text { Variance }\end{array}$ & $\begin{array}{l}\text { Total } \\
\text { Squares }\end{array}$ & $\begin{array}{l}\text { Degrees of } \\
\text { Freedom }\end{array}$ & $\begin{array}{l}\text { Mean } \\
\text { Squares }\end{array}$ & $\begin{array}{l}\text { Value of } \\
\text { Computerized p- }\end{array}$ & $\begin{array}{l}\text { Level of } \\
\text { Significance }\end{array}$ \\
\hline Teaching & Between Groups & 0.67 & 3 & 0.22 & 0.26 & 0.98 \\
& Within Groups & 121.08 & 145 & 0.83 & & \\
& Total & 121.75 & 148 & & & 0.89 \\
\hline Scholarly & Between Groups & 1.25 & 3 & 0.41 & 0.55 & \\
research & Within Groups & 108.63 & 145 & 0.74 & & 0.19 \\
& Total & 109.88 & 148 & & & \\
\hline Community & Between Groups & 1.91 & 3 & 0.63 & 0.76 & 0.92 \\
& Within groups & 119.41 & 145 & 0.82 & & \\
\hline Total score & Total & 121.32 & 148 & & & \\
& Between Groups & 1.67 & 3 & 0.55 & 0.80 & \\
& Within Groups & 98.69 & 145 & 0.68 & & \\
& Total & & 148 & & & \\
\hline
\end{tabular}


Table 9 noticed that there are no differences between the estimates of the study sample individuals of the degree of their practicing the functional roles due to a variable Academic rank according to the total degree. That is because all faculty members, whether at the University of Palestine or Al-Huson University College, exercise the same roles regardless of their academic ranks, especially that teaching, scientific research, and community service are essential functions for continuing university education the achievement of its goals.

\section{Recommendations}

In light of the results of the study, the researcher recommends the following:

- Holding training workshops, meetings, and meetings for faculty members at Palestine Technical University and Al-Huson University College to transfer skills and exchanging experiences and knowledge and developing creativity and solving problems for community service the local.

- Strengthening the relationship between the university and the local community by providing the necessary scientific research, educational and cultural activities that help develop the local community.

- The two universities should provide all material and moral facilities to encourage their faculty members to carry out qualitative research and scientific innovations that help advance the local community.

- Providing students with material and moral incentives to master self-learning and scientific research skills to serve the university and the local community.

- Conduct field studies on career roles for other groups in the Palestinian and Jordanian universities, such as students and administrators.

\section{Acknowledgments}

It is my great pleasure to thank my university (Palestine Technical University-Kadoorie) for all the encouragement and support to achieve my research.

\section{References}

Al-Amayreh, Muhammad. (2006). Appreciation of faculty members at Al-Isra University in Jordan for the educational tasks entrusted to them from the point of view of their students. Journal of Educational and Psychological Sciences, 7(3), 95-125.

Al-Farra, Ismail. (2004). Evaluation of the summer verbal teaching performance of teachers of the basic education stage. A working document submitted to the conference on quality in Palestinian university education: Al-Quds University for the period from 3/5/7/2004.

Al-Khatib, Ahmad. (2001). University Administration, Hamada Foundation for University Studies and Publishing and Distribution, Irbid, Jordan.

Al-Sarayra, Khaled. (2011). The job performance of faculty members in official Jordanian universities from the point of view of department heads in them. Damascus University Journal, 27(1+2), 26-39.

Al-Shaksy, Abdullah. (2006). Scientific Research and its Obstacles in Higher Education Institutions in the Sultanate of Oman from the Viewpoint of Academic Management and Faculty Members. Unpublished PhD Thesis, College of Graduate Studies, University of Jordan: Jordan.

Al-Tal Wael, \& Khaled, Al-Sarayra. (2013). The degree of Mu'tah University's interest in the quality of its role in serving the local community in light of the university's faculty members' estimates. Mu'tah for Research and Studies - Human and Social Sciences, 28(4), 35-70.

Ammar, Hamed. (1996). The Role of the Faculties of Education in Community Service and Environmental Development. The Thirteenth Annual Conference of the Department of Foundations of Education, Mansoura University: Egypt.

Boyd, C., \& Rush, B. (2002). Community service survey university of California santacruz. Retrieved from https://planning.ucsc.Edu/budget/officeprojects/commserv/commuityservcsurvey.htm

Frühwald, Wolfgang. (2003). Knowledge Culture or Knowledge Market? On the New Ideology of the University. Prospects, 33, 103-113.

Harahsha, Muhammad. (2013). Obstacles to scientific research among faculty members at Al al-Bayt University. Journal of the Universities Association for Education and Psychology, Syria, 11(3), 157-180.

Hariri, Rafideh. (2010). The Effectiveness of Educational Communication in Educational Institutions. Amman: Dar Al-Fikr. 
Hassan, Enas. (1995). Developing the goals of Egyptian university education in light of some global and local variables and future trends. The second annual national conference of the University Education Development Center "University Performance, Efficiency, Effectiveness and the Future", Ain Shams University, University Education Development Center.

Jeanette, T. (2001). The Impact of performance Indicators on the work of university Academic Evidence for Australian university. Higher Education Quarterly, 55(1), 42-61.

Jess Seegnileer. (1977). Job Satisfaction of Faculty and Staff at the College of Eastern Utah. Retrieved from https://eric.ed.gov/?id=ED139489

Kors, A. (1998). Charles and silver gatc the shadow university. NewYork, the free press.

Krishnakumar, R., \& RajeshKumar, M. (2011). Attitude of Teachers' of Higher Education towards e-Learning. Journal of Education and Practice, 2, 48-53. Retrieved from https://www.semanticscholar.org/paper/Attitude-of-Teachers'-of-Higher-Education-towards-KrishnakumarRajeshKumar/936ed3ec7aa60490bc4faa83b4ce0c9897289745

Ma'ani, Walid. (2002). Higher education in Jordan: a future vision within the conference on the future vision of education in Jordan.

Matouk, Khaled. (2016). Competencies and Roles of Faculty Members in the Department of Information Science at Umm Al-Qura University: An Analytical Descriptive Study. King Fahd National Library Journal, 22(2), 112-128.

Millcy, W., \& Gonsalves, Sonia. (2003). What You Don't Know Can Hurt You Students' Perceptions of Professors' Annoying Teaching Habits. College Students Journal, 37, p. 447. Retrieved from https://www.semanticscholar.org/paper/What-You-Don\%27t-Know-Can-Hurt-You\%3A-Students\%27-ofMiley-Gonsalves/40c673e4efcede69d8724724126dce22411a149e

Regional Office for the Arab States and the German United Nations Program. (2003). Arab Human Development Report 2003, Amman, Jordan.

Wani, Ibrahim, \& Siham, Ahmed. (2005). Activating the role of a faculty member in Egyptian universities in the field of community service. Journal of Education, 127(1), 2-17.

Wasus Dima (2015). The degree of practicing academic roles among faculty members at Al-Hussein Bin Talal University.

Zewailf, Mahdi, \& Al-Tarawanah, Tahsin. (1998). Methodology for Scientific Research. Amman: Dar Al-Fikr for Printing and Publishing.

\section{Copyrights}

Copyright for this article is retained by the author(s), with first publication rights granted to the journal.

This is an open-access article distributed under the terms and conditions of the Creative Commons Attribution license (http://creativecommons.org/licenses/by/4.0/). 